\title{
KINETIC AND ISOTHERM MODELING OF ADSORPTION OF DYES ONTO RICE HUSK CARBON
}

\author{
V.K. VERMA ${ }^{1}$ \\ A.K. MISHRA ${ }^{2, *}$
}

Received: $16 / 04 / 09$

Accepted: $14 / 04 / 10$

\author{
${ }^{1}$ Chemical Engineering Department \\ H.B. Technological Institute, Kanpur 208002, India \\ ${ }^{2}$ Chemical Engineering Department, \\ H.B. Technological Institute, Kanpur \\ 208002, India
}

*to whom all correspondence should be addressed: e-mail: vkchem@rediffmail.com

\section{ABSTRACT}

Rice husk carbon (RHC) has the ability to adsorb the dyestuff from aqueous solution. It may be useful low cost adsorbent for the treatment of effluents, discharged from textile industries. The effectiveness of RHC have been tested for the removal of colour from the wastewater samples containing three dyes namely crystal violet, direct orange and magenta. Effect of various parameters such as agitation time, $\mathrm{pH}$, temperature, adsorbent dose and concentration have been investigated in the present study. The adsorption of dyes have been best described by pseudo first order mechanism and Freundlich adsorption isotherms. The rate constant of adsorption $\left(K_{a d}\right)$ have been determined, which are found to be $6.8 \times 10^{-3}, 8 \times 10^{-3}$ and $10 \times 10^{-3} \mathrm{~min}^{-1}$ for crystal violet, direct orange and magenta respectively. Similarly the Freundlich constants related to the adsorption capacity $\left(\mathrm{K}_{\mathrm{f}}\right)$ are found to be $0.74,0.44$ and $0.68 \mathrm{~g} \mathrm{I}^{-1}$ and intensity of adsorption (n) are found to be $0.41,0.73$ and $0.33 \mathrm{mg} \mathrm{g}^{-1}$ for above dyes respectively.

KEYWORDS : wastewater, adsorption, dyestuff, rate constants, Freundlich isotherm.

\section{INTRODUCTION}

Textile industries discharged a large quantity of highly coloured wastewater effluent which are released into nearby land or rivers without any treatment because the conventional treatment methods are very expensive. On the other hand the low cost technologies don't allow a wishful colour removal and have certain disadvantages. Thus the removal of colour from effluents is one of the major environmental problem. In this concern adsorption process has been found to be more effective method for the treatment of dye containing wastewater. The most efficient and commonly used adsorbent is commercially activated carbon which is expensive and has regeneration problems. Recent investigations focused on effectiveness of low cost adsorbents like pearl millet husk (Selverani, 2000), neam leaf powder (Walker and Weatherly, 1998), coconut husk (Low and Lee, 1990), wheat straw (Robinson et al., 2002; Verma and Mishra, 2006), sewage sludge (Olereo et al.,2003), perlite (Dogan et al., 2000), maize cobs (Lin et al.,1987), wood (Poots et al.,1978), peat (Poots et al., 1976); natural adsorbent (Nassar and Guendi, 1991), banana pith (Namasivayam and Kanchana,1993), chitin (Annadurai and Krishnan, 1996), agricultural waste (Nawar and Doma, 1989) in the removal of dyes from wastewater effluent.

In the present study the adsorption of above three dyes onto rice husk carbon have been investigated. The effect of various parameters such as agitation time, $\mathrm{pH}$, temperature, adsorbent dose and concentration have been investigated in the batch experiments. 


\section{MATERIAL AND METHOD}

Three dyes namely crystal violet, direct orange (both are reactive dyes) and magenta (basic dye) were obtained from Thomas Baker (Chemicals) Ltd. Mumbai, India. The stock solution of these dyes were prepared in distilled water. The adsorbents were prepared by heating rice husk using muffle furnace. The masses obtained from the furnace were treated with concentrated sulphuric acid and washed with water to remove an excess acid and finally dried in sunlight. The physico-chemical characteristics of adsorbents are given in Table1.

Table 1. Physico-chemical characteristics of rice husk carbon

\begin{tabular}{cc}
\hline Parameters & Values \\
\hline Moisture content $(\%)$ & 15.38 \\
Bulk density $\left(\mathrm{g} \mathrm{ml}^{-1}\right)$ & 0.68 \\
Surface area $\left(\mathrm{m}^{2} \mathrm{~g}^{-1}\right)$ & 98.27 \\
Pore volume $\left(\mathrm{ml} \mathrm{g}^{-1}\right)$ & 0.12 \\
Average particle size $(\mu \mathrm{m})$ & 85 \\
Ash content $(\%)$ & 36.81 \\
$\mathrm{pH}$ & 6.8 \\
\hline
\end{tabular}

\subsection{Batch experiments}

Dye adsorption experiments were performed by taking $50 \mathrm{ml}$ stock solution of dye $\left(10 \mathrm{mg} \mathrm{l}^{-1}\right)$ and treated with $1 \mathrm{~g}$ of dose adsorbent. The variables studied were agitation time, $\mathrm{pH}$, temperature, adsorbent dose and concentration. After desire time of treatment samples were filtered to remove the adsorbent and progress of adsorption was determined spectro photometrically using spectronic20 (BAUSCH \& LOMB) at the wavelength for maximum absorbance $\left(\lambda_{\max }\right)$ which are 595,495 and $510 \mathrm{~nm}$ for crystal violet, direct orange and magenta respectively.

\subsubsection{Effect of agitation time (15, 30, 45, 60 and $75 \mathrm{~min})$}

The experiments were carried out by taking $50 \mathrm{ml}$ samples of dyes (concentration $10 \mathrm{mg} \mathrm{l}^{-1}$ ) in separate flasks and treated with $1 \mathrm{~g}$ of adsorbent dose at room temperature.

\subsubsection{Effect of $\mathrm{pH}(2,4,6,8$ and 10)}

The effect of $\mathrm{pH}$ was studied in the treatment of $50 \mathrm{ml}$ aqueous solution of dyes with $1 \mathrm{~g}$ dose of adsorbent. All the samples were treated for half an hour at fix temperature(room temperature).

\subsubsection{Effect of temperature $\left(20,40,60,80\right.$ and $\left.100^{\circ} \mathrm{C}\right)$}

The effect of temperature was investigated with $1 \mathrm{~g}$ dose of adsorbent mixing in $50 \mathrm{ml}$ aqueous solution of dyes (concentration $10 \mathrm{mg} \mathrm{l}^{-1}$ ) and the samples were treated for half an hour.

\subsubsection{Effect of adsorbent dose (0.5, 1.0, 1.5, 2.0 and $2.5 \mathrm{~g})$}

The study was carried out with different dose of adsorbent of $85 \mu$ m average particle size. The concentrations of samples were $10 \mathrm{mg} \mathrm{l}^{-1}$ and treated at fix temperature for half an hour.

\subsubsection{Effect of concentration: $\left(10,20,30,40\right.$ and $\left.50 \mathrm{mg} \mathrm{l}^{-1}\right)$}

The samples were treated with constant dose of adsorbent for half an hour at fix temperature.

\section{RESULTS AND DISCUSSION}

\subsection{Adsorption of dyes}

The adsorption of dyes were investigated in the study using different parameters such as agitation time, $\mathrm{pH}$, temperature, adsorbent dose and concentration.

\subsubsection{Effect of agitation time}

The samples of three dyes were taken in separate flasks and treated with $1.0 \mathrm{~g}$ dose of adsorbent. The variation in percent removal of dyes with the elapsed time has been shown in Figure 1. It is evident from the figure that RHC treatment resulted in $70 \%$ removal of crystal violet in first 15 min, which increased up to $82.5 \%$ in $60 \mathrm{~min}$. It also shows that the percent removal of direct orange and magenta are $47 \%$ and $54 \%$ in $15 \mathrm{~min}$, which increased up to $77 \%$ and $84 \%$ in 45 min respectively for both the dyes. The optimum time is $45 \mathrm{~min}$ for both the dyes at which equilibrium is obtained. The 
present observations are in conformity with the other investigators(Verma and Mishra, 2004; Khatri and Singh, 2000). The increase in the extent of removal of dyes with increasing time because adsorbate generally formed monolayer on the surface of adsorbent. Thus the removal of dyes from aqueous solution is controlled by the rate of transport of the adsorbate species from the outer sites to the interior sites of adsorbent.

\subsubsection{Effect of $\mathrm{PH}$}

The aqueous solution of dyes having concentration of $10 \mathrm{mg} \mathrm{l}^{-1}$ were treated by $1 \mathrm{~g}$ dose of adsorbent for half an hour with varying $\mathrm{pH} 2$ to 10 . The $\mathrm{pH}$ was maintained with the help of $0.1 \mathrm{~N}$ $\mathrm{HCl}$ and $0.1 \mathrm{~N}-\mathrm{NaOH}$ solution (Figure 2). It is evident from the figure 2, that when the aqueous solution of dyes were treated with $\mathrm{RHC}$, it was found that $80 \%$ removal of crystal violet at $\mathrm{pH} 2$ and $85 \%$ at $\mathrm{pH} 10$. In case of direct orange the removal was increased from 62 to $85 \%$. The equilibrium reached in the acidic medium at $\mathrm{pH} 6$ for both the dyes. However in case of magenta the removal was observed to be 45 to $73 \%$ in the same conditions and equilibrium obtained at $\mathrm{pH} 8$.

The removal of dyes are more at higher $\mathrm{pH}$, because the surface of activated carbons are negatively charged (Helfferich, 1963), the decrease in adsorption capacity in the low pH region would be expected as the acidic medium would lead to an increase in hydrogen ion concentration which would then neutralize the negatively charged carbon surface thereby decreasing the adsorption of the positively charged cation because of reduction in the force of attraction between adsorbate and adsorbent.

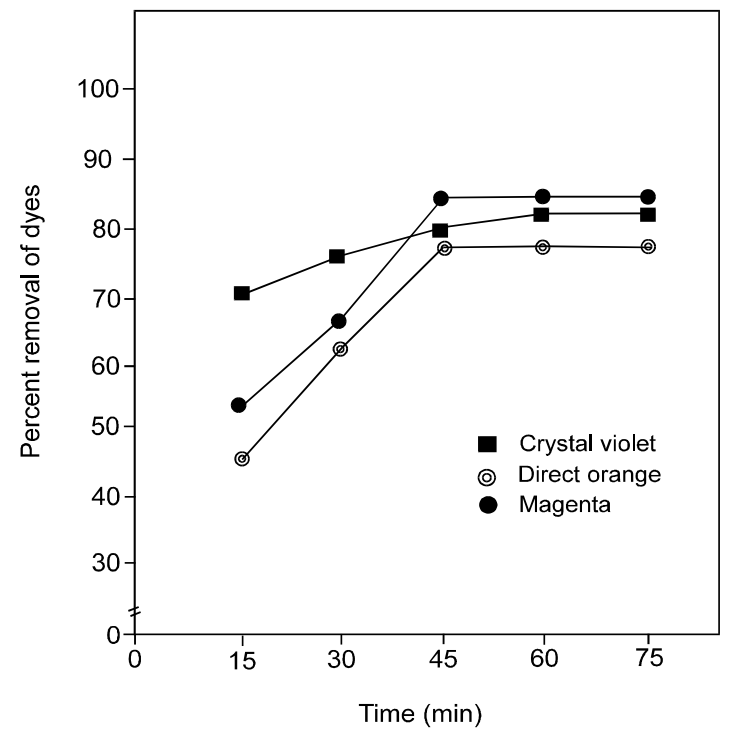

Figure 1. Effect of agitation time in the removal of dyes by $\mathrm{RHC}$

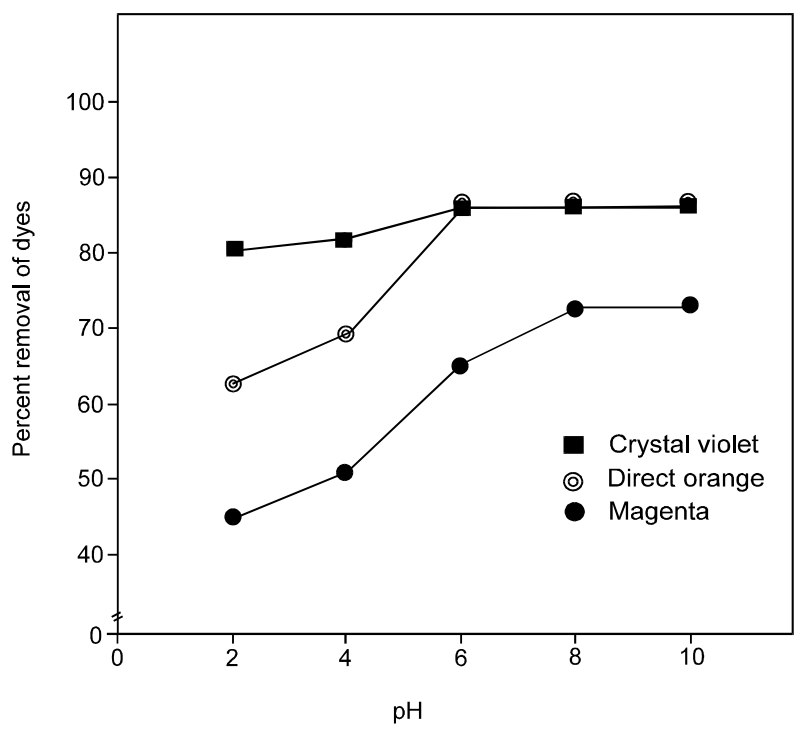

Figure 2. Effect of $\mathrm{pH}$ in the removal of dyes by RHC

\subsubsection{Effect of temperature}

To study the effect of temperature on the removal of dyes the experiments were carried out at temperature varying from 20 to $100{ }^{\circ} \mathrm{C}$. It was observed that the removal of crystal violet was found to be 80 to $87.5 \%$, removal of direct orange and magenta were found to be 69.2 to $85 \%$ and 50 to $80 \%$ respectively keeping the other parameters are constant. The results have been shown in Figure 3 . It is revealed from the figure 3 , that the removal of dyes with temperatures would increase the mobility of the ions of dyes and produces a swelling effect within the internal structure of adsorbent, thus enabling the large molecules of dyes to penetrate further (Mckay, 1982; Hiroyuki et al., 1994a; Admson, 1980; Setheraman, 1973; Saker and Podar, 1994; Mall and Upadhyaya, 1995).The temperature affect the rate of removal of dyes by altering the molecular interactions and the solubility of dyes (Pandey et al.,1989). The greater removal of dyes due to increasing temperature may be more interaction between adsorbate and adsorbent (Pandey et al., 1988; Hiroyuki et al., 1994b).

\subsubsection{Effect of adsorbent dose}

The effect of adsorbent dose was also investigated for the removal of dyes from aqueous solution. The experiments were carried out with adsorbent dose varied from 0.5 to $2.5 \mathrm{~g}$ with keeping other 
parameters are constant. The removal of dyes were found to be 70 to $77.5 \%, 54$ to $69 \%$ and 67 to $89 \%$ in case of crystal violet, direct orange and magenta respectively (Figure 4). The increase in removal of dyes with adsorbent dose due to the introduction of more binding sites for adsorption. Similar results have been reported by the other investigators (Namasivayam and Yamuna, 1994; Sarioglu and Atay, 2006).

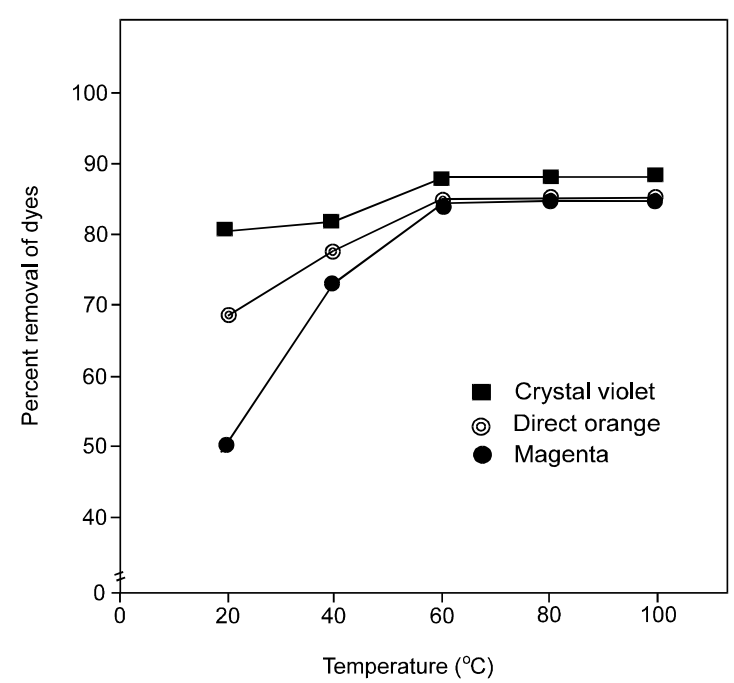

Figure 3. Effect of temperature in the removal of dyes by $\mathrm{RHC}$

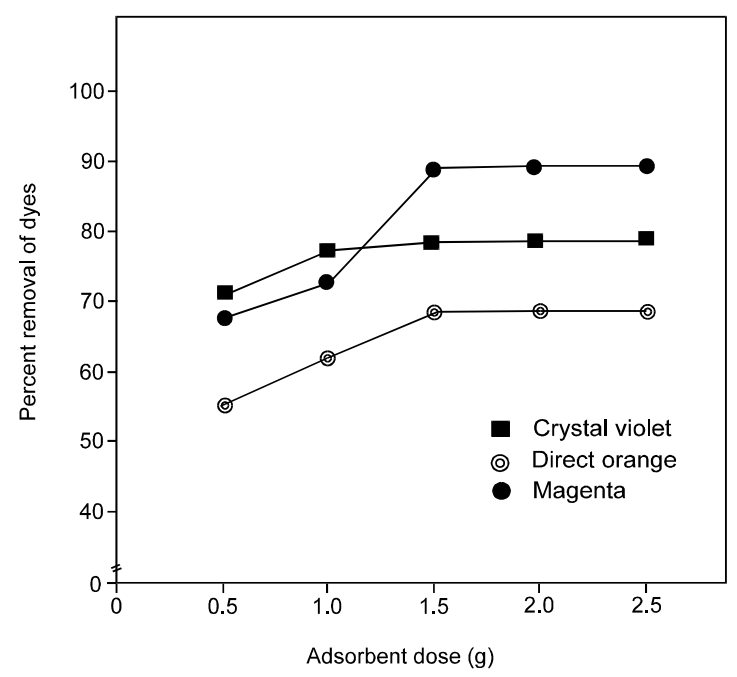

Figure 4. Effect of adsorbent dose in the removal of dyes by $\mathrm{RHC}$

\subsubsection{Effect of concentration}

The effect of concentration of dyes (10 to $50 \mathrm{mg} \mathrm{l}^{-1}$ ) have been also tested with constant dose of adsorbent. The removal of dyes decreased from 82.5 to $70 \%$ in case of crystal violet, 75 to $47 \%$ in case of direct orange and 84 to $54 \%$ in case of magenta. The results indicated that the adsorption of dyes are much dependent on concentration of solution. These observations are in close agreement with that reported (Verma and Mishra, 2005; Garg et al., 2003; Gupta et al., 1988) for removal decreases with increase initial concentration of dyes.

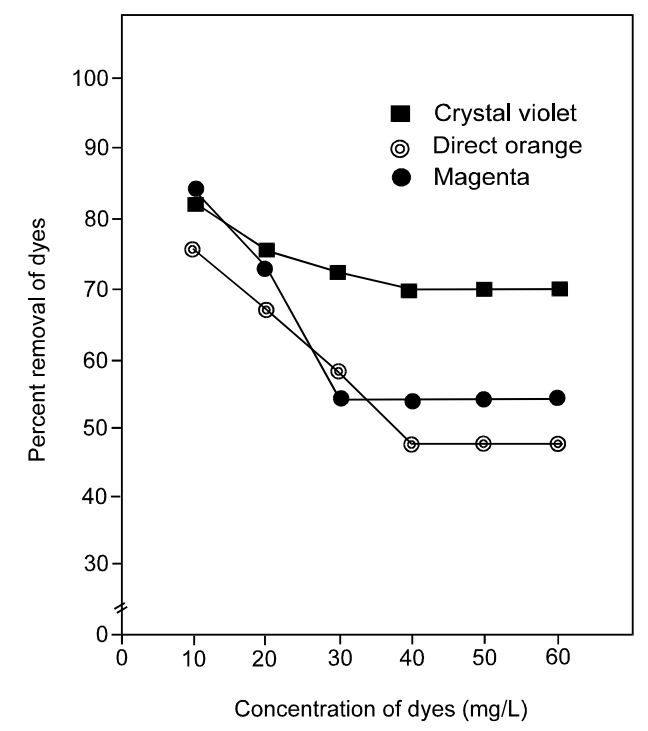

Figure 5. Effect of concentration in the removal of dyes by RHC 


\subsection{KINETIC MODEL OF ADSORPTION}

In order to determine the controlling mechanism of adsorption process such as mass transfer and chemical reaction, the first order kinetic model is used to test the experimental data. A simple kinetics of adsorption is given by Lagergren rate equation.

$$
\frac{\mathrm{dq}_{\mathrm{t}}}{\mathrm{d}_{\mathrm{t}}}=\mathrm{K}_{\mathrm{ad}}\left(\mathrm{q}_{\mathrm{e}}-\mathrm{q}_{\mathrm{t}}\right)
$$

where $K_{a d}$ is the rate constant of first order adsorption; $q_{e}$ is the amount of dye adsorbed at equilibrium and $\mathrm{q}_{\mathrm{t}}$ is the amount of dye adsorbed at time.

Applying conditions:

$\mathrm{q}_{\mathrm{t}}=0$ at $\mathrm{t}=0$

$\mathrm{q}_{\mathrm{t}}=\mathrm{q}_{\mathrm{t}}$ at $\mathrm{t}=\mathrm{t}$

$\log \left(q_{e}-q_{t}\right)=\log q_{e}-\frac{K_{a d} t}{2.303}$

Based on experimental results, linear plots of $\log \left(q_{e}-q_{t}\right)$ versus $t$ suggest the applicability of Lagergren first order equation (Figure 6). The rate constant was calculated from the slopes and values are given in Table 2 . The effect of dye concentration on rate constants $\left(k_{a d}\right)$ helps to describe the mechanism of removal of dyes from aqueous solution.

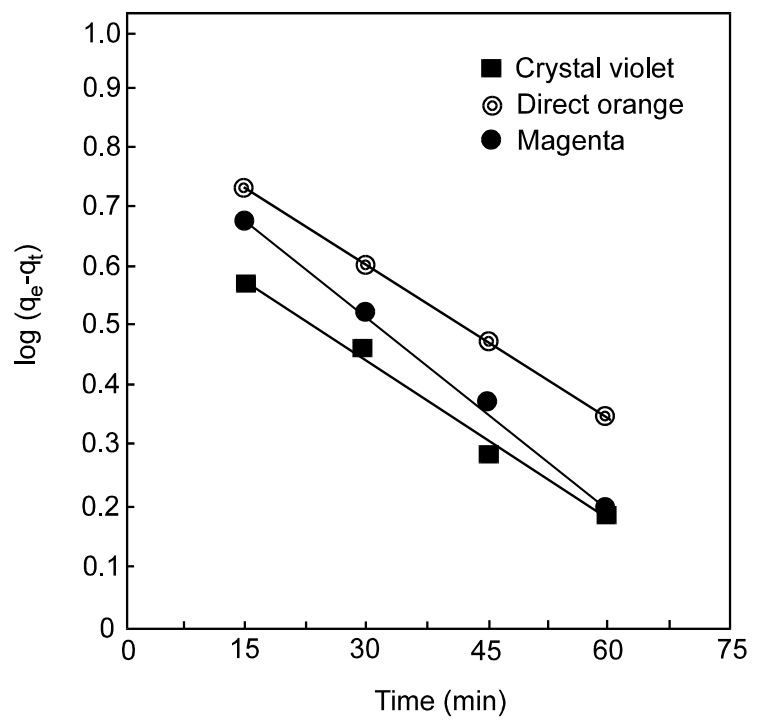

Figure 6. Test of pseudo first order equation for adsorption of dyes by RHC

Table 2. Adsorption rate constant $\left(\mathrm{K}_{\mathrm{ad}}, \mathrm{min}^{-1}\right)$ for different dyes

\begin{tabular}{cc}
\hline Name of dyes & $\mathbf{K}_{\mathrm{ad}}, \mathbf{m i n}^{-1}$ \\
\hline Crystal violet & $6.8 \times 10^{-3}$ \\
Direct orange & $8 \times 10^{-3}$ \\
Magenta & $10 \times 10^{-3}$ \\
\hline
\end{tabular}

\subsection{ADSORPTION ISOTHERMS}

The distribution of dye between the liquid phase and adsorbent is a measure of the position of equilibrium in the adsorption process and can be generally expressed by a most common theory i.e. Freundlich isotherm model.

\subsubsection{Freundlich isotherm model}

The equilibrium data obtained with varying dose of adsorbent and fixed concentration of dyes confirm to the Freundlich equation as given below:

$\mathrm{q}_{\mathrm{e}}=\frac{\mathrm{x}}{\mathrm{m}}=\mathrm{K}_{\mathrm{f}} \mathrm{C}_{\mathrm{e}}^{1 / \mathrm{n}}$

$\log q_{e}=\log K_{f}+\frac{1}{n} \log C_{c}$ 
where $x$ is the amount of dye adsorbed $\left(\mathrm{g} \mathrm{I}^{-1}\right)$ and $\mathrm{m}$ is the mass of adsorbent used, $\mathrm{C}_{e}$ is the equilibrium concentration of dyes, $K_{f}$ and $n$ are the constants incorporating factors affecting the adsorption process such as adsorption capacity and intensity of adsorption respectively.

The values of $K_{f}$ and $n$ are obtained from the intercept and slope of the graph plotted between log $q_{e}$ versus $\log C_{e}$ (Figure 7). The values of $n$ are lie between 0 and 1 (Table 3 ), indicated that the adsorption is favourable with the Freundlich isotherm model. The similar results were earlier reported by the other investigators (Khan et al., 2004).

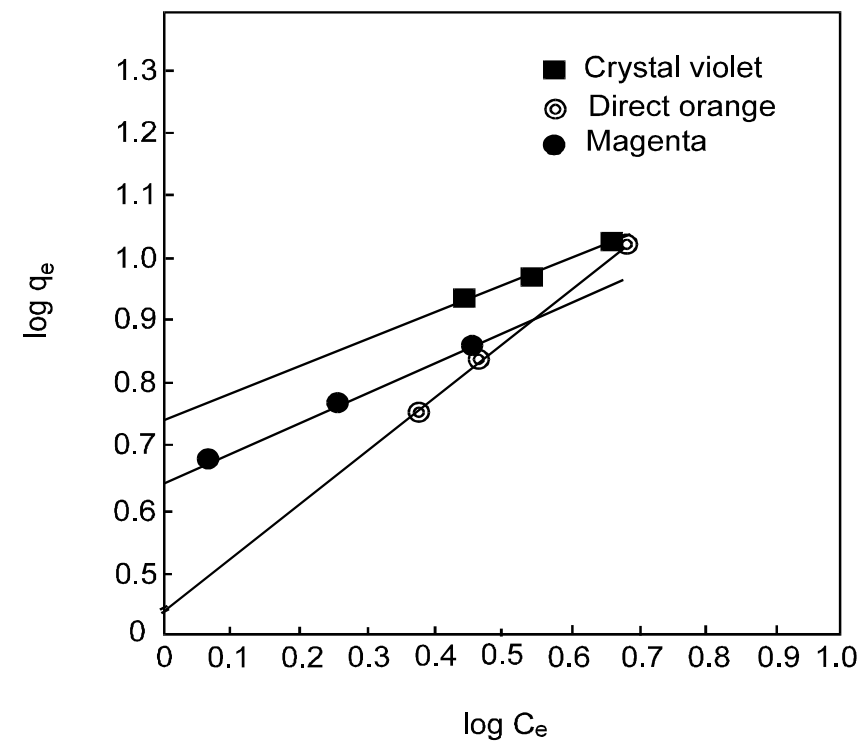

Figure 7. Freundlich isotherm for adsorption of dyes by RHC

Table 3. Values of $\mathrm{k}_{\mathrm{f}}$ and $\mathrm{n}$ for different dyes

\begin{tabular}{ccc}
\hline Name of dyes & $\mathbf{K}_{\mathbf{f}}$ & $\mathbf{n}$ \\
\hline Crystal violet & 0.74 & 0.41 \\
\hline Direct orange & 0.44 & 0.73 \\
\hline Magenta & 0.68 & 0.38 \\
\hline
\end{tabular}

\section{CONCLUSION}

The adsorption of dyes namely crystal violet, direct orange and magenta on RHC have been tested by First order kinetic model and Freundlich adsorption isotherm. The values of first order rate constant $\left(K_{a d}\right)$ are $6.8 \times 10^{-3}, 8 \times 10^{-3}$ and $10 \times 10^{-3} \mathrm{~min}^{-1}$ for above dyes respectively. The effect of dye concentration on rate constants $\left(\mathrm{K}_{\mathrm{ad}}\right)$ helps to describe the mechanism of removal of dye. Similarly the values of Freundlich constants (n) are $0.41,0.73$ and 0.38 for the above dyes respectively. These values of $n$ are lie between 0 and 1 for all the dyes suggested the applicability of Freundlich adsorption isotherm.

Thus it is concluded that RHC has an ability to adsorb the dyestuffs from aqueous solution and it could be used as a cheap substitute of commercially available adsorbents for decolourising wastewater effluents.

\section{REFERENCES}

Admson A.W. (1980), Physical Chemistry of Surface, Interscience Publisher, New York.

Annadurai G. and Krishnan M.R.V. (1996), Adsorption of basic dye on chitin, Indian J. Environ. Protection, 16, 444-449.

Dogan M. Alkan M. and Onganer Y. (2000), Adsorption of methylene blue from aqueous solution onto perlite, Water Air \& Soil Pollution, 120, 229-248.

Garg V.K. Gupta R. Yadav B. and Kumar R. (2003), Removal of acid dyes by low cost adsorbent, Bioresour. Technology, 89, 121-124.

Gupta G.S. Prasad G. and Singh V.N. (1988), Removal of Chrome dye from water by fly ash, JAWPC Technical Annual, 15, 98-103. 
Helfferich F. (1963), Ion Exchange, McGraw Hill, New York.

Hiroyuki H. Fukudas M. Okamato A. and Kataoka T. (1994), Adsorption of acid dye cross linked chitosan Fibers Equilibria, Chem. Engg. Sci., 48(12), 2267-2272.

Hiroyuki H. Hideki N. and Kataoka T. (1994) Adsorption of BSA on strongly basic chitosan - Eqiulibria, Biotechnol. Bioengineering, 43, 1087-1093.

Khan T.A. Singh V. and Kumar D. (2004), Removal of some basic dyes from artificial textile wastewater by adsorption on Akash Kinari Coal, J. Sci. \& Ind. Research, 63, 335-364.

Khatri S.D. and Singh M.K. (2000), Colour removal from synthetic dye wastewater using a biosolid sorbent, Water, Air \& Soil Pollution, 120(3-4), 283-294.

Lin S.H. (1987), Adsorption of disperse dye on various adsorbents, J. Chem. Technol. Biotechnology, 28, 99-104.

Low K.S. and Lee C.K. (1990), The removal of cationic dyes using coconut husk as sorbent, J. Pertanika, 13, 221-226.

Mall I.D. and Upadhyaya S.N. (1995), Removal of basic dyes from wastewater using boiler bottom ash, Indian J. Environ. Health, 27, 1-10.

Mckay G. (1982), Adsorption of dyestuffs from aqueous solution with activated carbon : 1 : Equilibrium and batch contact time studies, J. Chem. Technol \& Biotechnol., 32, 759-772.

Namasivayam C. and Kanchana N. (1993), Removal of congo red from aqueous solution by waste banana pith, J.Partanika, 1, 33-39.

Namasivayam C. and Yamuna R.T. (1994), Utilizing biogas residual slurry for dye adsorption, Amer. Dyestuff Rep. Aug, 235-239.

Nassar M.M. and Guendi M.S. (1991), Comparative cost of colour removal from textile effluents using natural adsorbents, J. Chem. Technol. Biotechnology, 50, 252-259.

Nawar S.S. and Doma H. (1989), Removal of dyes from effluents using low-cost agricultural by-products, Sci. Total Environment, 79, 271-279.

Otero M. Rozada M. Calvo L.F. Garcia A.I. and Moran A. (2003), Kinetic and Equilibrium modeling of methylene blue from solution by adsorbent materials produced from sewage sludges, Biochemical Engineering Journal, 15, 59-68.

Pandey K.K. Prasad G. and Singh V.N. (1989), Use of wallstronite for the treatment of $\mathrm{Cu}(\mathrm{II})$ rich effluent, Water Research, 19, 869-872.

Pandey K.K. Prasad G. and Singh V.N. (1988), Copper removal from aqueous solution by fly ash, Water Air \& Soil Pollution, 27, 287-292.

Poots V.J.P. Mckay G. and Healy J.J. (1976), The removal of acid dye from effluent using natural adsorbents-I Peat, Water Research, 10, 1061-1066.

Poots V.J.P. Mckay G. and Healy J.J. (1978), Removal of basic dye from effluent using wood as an adsorbent, Water Pollution Control Federation, 50, 926-931.

Robinson T. Chandaran B. and Nigam P. (2002), Removal of dyes from a synthetic dye effluent by biosorption on wheat straw, Water Research, 36, 2830-2842.

Saker M. and Podar S. (1994), Study of adsorption of methyl violet onto flyash, Proc. Ind. Annual Communication, 31, 213-215.

Sarioglu M. and Atay U.A. (2006), Removal of Methylene blue by using biosolid, Global NEST J., 8(2), 113-120.

Selverani K. (2000), Studies on low cost adsorbents for the removal of organics and inorganic from wastewater, Ph.D Thesis, REC, Tiruchirapalli, India.

Setheraman N.V. (1973), Adsorption of dyes by clay minerals and its applications to colour removal, M.Tech. Thesis, Deptt. of Civil Engineering, IIT Kanpur,India.

Verma V.K. and Mishra A.K. (2004), Effectiveness of rice husk carbon for the removal of colour" Asian J. Microbiol. Biotechnol. Environ. Sciences, 6(2), 221-222.

Verma V.K. and Mishra A.K. (2005), Dye removal by Sawdust based adsorbent, Pollution Research, 24 (1), 97-99.

Verma V.K. and Mishra A.K. (2006), Removal of dyes by the wheat straw carbon, Ecol. Environ. \& Conservation, 12 (4), 755-757.

Walker G.M. and Weatherly L.R. (1998), Fixed bed adsorption on acid dyes onto activated carbon, Environ. Pollution, 99, 133-136. 